\title{
Congenital Cytomegalovirus-History, Current Practice, and Future Opportunities
}

\author{
Jim Thigpen, PharmD, BCPS ๑
}

\section{Continuing Nursing Education (CNE) \\ Credit}

The test questions are provided in this issue. The posttest and evaluation must be completed online. Details to complete the course are provided online at academyonline. org. Sign into your ANN account or register for a non-member account if you are not a member. A total of 1.4 contact hour(s) can be earned as CNE credit for reading this article, studying the content, and completing the online posttest and evaluation. To be successful, the learner must obtain a grade of at least 80 percent on the test. The test expires three (3) years from the publication date of this journal. Disclosures: The members of the activity planning committee and the test panel have no relevant financial interests or affiliations with any commercial interests related to the subjects discussed within this article. No commercial support or sponsorship was provided for this educational activity. Neither ANN nor ANCC endorses any commercial products discussed/displayed in conjunction with this educational activity.

The Academy of Neonatal Nursing is accredited with distinction as a provider of continuing nursing education by the American Nurses Credentialing Center's Commission on Accreditation. Provider, Academy of Neonatal Nursing, approved by the California Board of Registered Nursing, Provider \#CEP 6261; and Florida Board of Nursing, Provider \#FBN 3218, CE Broker \# 50-3066.

The purpose of this column is to update the reader on the current knowledge and practice pertaining to congenital cytomegalovirus infection.

Jim Thigpen has no conflicts of interest to declare.

Column editor: Jim Thigpen

\begin{abstract}
Cytomegalovirus (CMV) was first identified in the 1950s and noted to cause newborn disease in the 1960s. It is now known to be the most common cause of congenital infection in the world, leading to various central nervous system sequelae, the most common being hearing loss. Cytomegalovirus is a ubiquitous pathogen that affects nearly 30,000 infants annually in the United States, leading to 3,000-4,000 cases of hearing loss. Prevention through vaccination has proved unreliable, as has the use of immune globulin. Prevention through education has been shown to be the most effective method of minimizing infection. Antiviral therapy is effective at reducing the impact of infection on newborns. Continued global efforts will hopefully provide more solutions for this opportunistic infection.
\end{abstract}

Keywords: cCMV; infection; newborn screening; sensorineural hearing loss; valganciclovir; virus

$\mathrm{C}$

YTOMEgalovirus (CMV) IS A MEMBER OF the human herpesvirus family (herpesvirus 5 ) that also includes herpes simplex 1 and 2, varicella zoster virus, and others. ${ }^{1}$ Cytomegalovirus is the most common congenital infection in the world, with an increased prevalence noted in crowded conditions and developing areas. ${ }^{2}$ In the United States, 30,000 infants are affected annually, with the incidence of congenital cytomegalovirus (cCMV) infection ranging from 0.5 to 2 percent of all live births. ${ }^{2}$ Cytomegalovirus seroprevalence in women of childbearing age ranges from 50 to 85 percent in developed countries to nearly 100 percent in developing countries, where the virus is acquired through breastfeeding or crowded living conditions. ${ }^{3}$

The purpose of this column is to provide an overview of the history, epidemiology, clinical findings, prevention, current treatment, and prognosis of CMV infection in the mother and infant.
HISTORY OF CMV INFECTION

"Cytomegalic Inclusion Disease," first described in 1956, is broadly characterized as a disease acquired from an infectious cause. ${ }^{4}$ One decade later, researchers identified a more specific primary mode of transmission, namely contact with infected urine or saliva. ${ }^{5}$ The first case of "cytomegalic inclusion disease of the newborn" was published in 1960 in the journal Pediatrics. ${ }^{6}$ The infant presented with a generalized petechial rash and hepatosplenomegaly. Other commonly reported clinical findings of congenitally infected infants include microcephaly, spasticity, chorioretinitis, cerebral calcifications, developmental delay, deafness, seizures, blindness, and optic atrophy. ${ }^{5}$

\section{EPIDEMIOLOGY}

Cytomegalovirus is ubiquitous in humans and usually causes an asymptomatic or selflimited infection in healthy children and 
adults; however, it is a major cause of significant sequelae in congenitally infected infants and in the immunocompromised. ${ }^{2}$ After a primary infection in an immunocompetent person, CMV remains in the bone marrow in a lifelong latency stage. The virus is reactivated from this reservoir in the CD24+ stem cells and can be triggered by immunosuppression. ${ }^{1} \mathrm{CMV}$ is unique in that it can establish secondary persistent infection despite the presence of high titers of CMV-neutralizing antibodies. This is known as a "superinfection" and can occur in previously-exposed, immunocompetent individuals. ${ }^{7}$

Intrauterine transmission of CMV occurs secondary to a primary or nonprimary maternal CMV infection. Primary infection refers to pregnant females who first acquire the virus during pregnancy and is responsible for approximately 75 percent of all cases of cCMV. In fact, primary CMV infections are associated with the greatest risk for in utero transmission (30-35 percent). ${ }^{3}$ Alternatively, pregnant females with preexisting CMV IgG antibodies are classified as having a nonprimary CMV infection; the rate of intrauterine transmission is significantly lower with nonprimary infections (1.1-1.7 percent). ${ }^{3}$

\section{CLINICAL FINDINGS}

\section{Antenatal}

Imaging tests used during pregnancy to detect morphologic features include targeted ultrasound and magnetic resonance imaging (MRI). Common findings include microcephaly, ventriculomegaly, intracranial calcifications, periventricular echogenicity, and cortical migrational abnormalities. Outside of the central nervous system (CNS), other complications include hepatosplenomegaly, bowel hyperechogenicity, and growth restriction. ${ }^{8}$

\section{Postnatal}

Of infected infants, approximately $10-15$ percent present with symptomatic disease. ${ }^{2}$ Clinical expressions vary from mild, transitory findings to severe multisystem dysfunction that can include intrauterine growth restriction, petechiae, jaundice, hepatosplenomegaly, microcephaly, chorioretinitis, and sensorineural hearing loss (SNHL). A more complete list of signs and symptoms encountered in cCMV can be found in Table $1 .{ }^{9}$

While maternal to fetal transmission risk increases with advancing gestational age, fetal morbidity risks are highest when infection occurs in the early stages of pregnancy. ${ }^{3}$ Among infants with cCMV infection, the two most common long-term sequelae are SNHL and neurodevelopmental delay. ${ }^{2}$ Hearing loss is reported in approximately 50 percent of symptomatic infants and 10-15 percent of asymptomatic infants. Cytomegalovirus-related hearing loss typically presents after the newborn period and may be associated with progressive hearing loss. In a 2019 study, Faure-Bardon and colleagues found that maternal primary CMV infection in the first trimester was exclusively linked to fetal SNHL

\section{TABLE 1 Possible Signs and Symptoms in Children with cCMV}

Clinically Detectable Signs on Physical Examination

Small for gestational age (birth weight $<-2$ SD for gestational age)

Microcephaly (head circumference $<-2$ SD for gestational age)

Petechiae or purpura (usually found within hours of birth and persist for several weeks)

Blueberry muffin rash (intradermal hematopoiesis)

Jaundice*

Hepatomegaly

Splenomegaly

Neurologic Examination

Microcephaly (head circumference $<-2$ SD for gestational age)

Neurologic signs (lethargy, hypotonia, seizures, poor sucking reflex)

Abnormalities detected incidentally or through subsequent investigations/specialist examination

Laboratory Results

Blood Tests

Anemia

Thrombocytopenia (occurs in the first week of life, but platelets often increase spontaneously after the second week)

Leukopenia, isolated neutropenia

Elevated liver enzymes (ALT/AST)

Conjugated hyperbilirubinemia

Cerebrospinal Fluid Tests

Abnormal cerebral fluid indices

Positive CMV DNA

Neuroimaging

Calcifications

Periventricular cysts

Ventricular dilation

Subependymal pseudocysts

Germinolytic cysts

White matter abnormalities

Cortical atrophy

Migration disorders

Cerebellar hypoplasia

Lenticulostriatal vasculopathy

Hearing Test

SNHL or bilaterally

Visual Examination

Chorioretinitis

Retinal hemorrhage

Optic atrophy

Strabismus

Cataracts

*CMV-associated jaundice can be present on the first day after birth and usually persists longer than physiologic jaundice.

Abbreviations: ALT = alanine aminotransferase; AST = aspartate aminotransferase; $\mathrm{cCMV}=$ congenital cytomegalovirus; $\mathrm{CMV}=$ cytomegalovirus; $\mathrm{SD}$ = standard deviation; $\mathrm{SNHL}=$ sensorineural hearing loss.

Source: From Luck SE, Wieringa JW, Blazquez-Gamero D, et al. Congenital cytomegalovirus-A European expert consensus statement on diagnosis and management. Pediatr Infect Dis J. 2017;36(12):1206. Used with permission.

and/or neurologic morbidity. ${ }^{10}$ Congenital CMV has also been shown to manifest with uncommon disease processes 
including persistent pulmonary hypertension, ${ }^{11}$ intestinal malrotation, ${ }^{12}$ intraventricular hemorrhage ${ }^{13}$ isolated secretory diarrhea, ${ }^{14}$ nephrotoxicity, ${ }^{15}$ and respiratory distress syndrome, ${ }^{16}$ among others.

Perinatal CMV infection can occur if the newborn is exposed during childbirth or it may be caused by exposure through breastfeeding. Signs and symptoms of infection include thrombocytopenia, neutropenia, abnormal liver function tests, hepatomegaly, splenomegaly, and pneumatosis. ${ }^{6}$

\section{PREVENTION OF CMV INFECTION}

Women are most likely to become infected through close mucocutaneous contact with saliva, any contaminated item that may enter the mouth, or with urine. ${ }^{17}$ Therefore, the most effective preventative measure is proper personal hygiene. To facilitate proper hygiene, prenatal education should include a discussion of hygienic best practices and risks associated with poor hygiene. In a study by Revello and colleagues, published in 2015, of over 600 seronegative women at conception, women who received detailed hygiene information incurred a 1.2 percent seroconversion risk and 0.9 percent transmission risk. ${ }^{17}$ Women who underwent routine pregnancy counseling incurred a 7.6 percent seroconversion risk and maternal-fetal transmission risk of 2.5 percent. Experts contend that focused counseling specific to maternal personal hygiene during pregnancy should be adopted as a standard of practice and could reduce the incidence of primary CMV infections by 75 percent. $^{18}$

Following maternal seroconversion, there is a lack of maternal antibodies that could prevent maternal-fetal transmission. In a study by Revello and colleagues, mothers were given hyperimmune globulin or placebo following primary infection. ${ }^{19}$ The transmission rate at delivery was 30 percent in the treatment group and 44 percent in the placebo group. However, the lack of statistical significance has been questioned because of the study being underpowered, as well as the frequency of immunoglobulin administration. Additionally, the hyperimmune globulin group experienced a higher number of adverse obstetrical events than in the placebo group (13 vs 2 percent). This research has yielded conflicting results, and the current recommendation is that immunoglobulin treatment not be routinely administered to pregnant women with primary CMV infection. ${ }^{7}$

\section{Immunization}

Large-scale development and implementation of immunization programs is considered one of the most significant public health achievements of the 20th century. ${ }^{20}$ As the rubella vaccine virtually eliminated congenital rubella syndrome in the United States, a maternal CMV vaccine that stimulates protective immune responses is needed. Unfortunately, natural CMV infection, even though it elicits a robust immune response, does not protect the mother against superinfection or eliminate mother-to-fetus transmission. Live-attenuated CMV vaccines have not successfully boosted immune responses in seropositive individuals and failed to prevent primary CMV infection among seronegative women exposed to young children actively shedding CMV. There has been some progress in transplant patients with attempts to make livevirus vaccines more effective by co-administration with interleukin-12. ${ }^{20}$ Future studies may explore this platform for the prevention of CMV infection in pregnancy. Also, the human species-specific characteristic of CMV makes animal testing of CMV vaccines challenging in evaluating clinical outcomes. Finally, other important features to consider in maternal immunization research studies are legal factors. As pregnancy complications are not unusual, pharmaceutical and vaccine manufacturers may be less willing to pursue vaccine development given the high financial risks involved.

\section{DIAGNOSIS OF CMV INFECTION}

Even in cases of suspected or confirmed primary maternal CMV infection, there is no reliable way to diagnose or exclude fetal CMV infection early in pregnancy. Guerra and colleagues studied primary CMV infection in 600 pregnant women, and in 549 pregnancies, no fetal signs of transmission were found on ultrasound. ${ }^{21}$ In the 51 cases where ultrasound findings of fetal infection were discovered, only one-third were later found to have clinical or laboratory findings of CMV infection. The use of amniocentesis is the only reliable method of in utero cCMV diagnosis. However, this procedure is done at 20 weeks' gestation or later and at least six weeks after the estimated time of maternal infection. ${ }^{22}$

Congenital CMV infection fulfills the general criteria of the American College of Medical Genetics required for consideration as a condition targeted for a newborn screening program. Through screening, cCMV could be identified at a time when it would not ordinarily be detected clinically; there are demonstrated benefits of early detection, timely intervention, and efficacious treatment of the condition. ${ }^{2}$ Currently, the standard diagnostic tool for cCMV in newborns is a viral culture of urine or saliva and dried-blood spot (DBS) samples. ${ }^{2}$ The assay is labor-intensive, costly, requires tissue-culture lab facilities, and takes several days to yield results. Moreover, it is difficult to employ this assay for large scale screening of infants. Nucleic acid amplification techniques, such as polymerase chain reaction (PCR), are being used more frequently for the diagnosis of viral infection because this test offers the advantages of greater sensitivity, significant specificity, and rapid turnaround. ${ }^{23}$ The testing of infant saliva takes advantage of the fact that CMV displays a high level of replication in the salivary gland and there is constantly shedding of virus into the saliva, even in asymptomatic patients. A study of nearly 35,000 infants in the United States, using a quantitative PCR-based assay detected a total of 177 cases of cCMV. ${ }^{24}$ These results were directly compared to culture-testing and, in liquid saliva the sensitivity and specificity of 100 percent and 99.9 percent, respectively. In dried saliva, the sensitivity and specificity of the assay were 97.4 percent and 99.9 percent, respectively. Accordingly, quantitative 
PCR assays of both liquid- and dried-saliva samples exhibited high sensitivity and specificity for detecting CMV infection in newborns. PCR techniques have also been used in samples of urine and found to have nearly identical results when compared to saliva. ${ }^{23}$ The collection of urine samples can also have an impact on the reliability of the test. Urine that is collected by placing a cotton ball in the diaper is less sensitive in CMV detection when compared to a specimen collected using a urine collection bag. ${ }^{23}$ Dried-blood spot samples are also utilized in developed countries for newborn metabolic and genetic screening programs. It is reasonable to consider the use of the collected DBS samples for diagnosis of cCMV in infants. If this is a reliable medium, it could alleviate the need for collection of additional saliva or urine samples for a universal screening program. Unfortunately, in a study of over 20,000 newborns, the PCR results from DBS samples identified fewer than 40 percent of the CMVinfected infants. ${ }^{25}$

\section{TREATMENT OPTIONS}

\section{Prenatal Treatment}

Antiviral therapy in women with CMV infection in pregnancy has been investigated and reported in the literature. The optimal antiviral medication for CMV infection in children and adults is valganciclovir. However, despite successful use in limited case reports severe neutropenia often precludes its use. ${ }^{26}$ An alternative option is valacyclovir, an antiviral medication that acts to inhibit DNA synthesis and viral replication. ${ }^{26}$ Leruez-Ville and associates treated 43 mothers with fetuses noted to have mild to moderate cCMV infection with $8 \mathrm{~g} /$ day of valacyclovir. ${ }^{27}$ Study data yielded results which included a reduced (20 percent) maternal-to-fetal CMV transmission rate. Larger studies are needed to evaluate this intervention and the long-term effects. At this time, there are no current recommendations for the use of antiviral therapy for the prevention or treatment of cCMV during pregnancy. ${ }^{26}$

\section{Postnatal Treatment}

Studies assessing treatment of $\mathrm{CCMV}$ in neonates started 30 years ago, with ganciclovir as the initial agent evaluated. The first large trial by Kimberlin and colleagues, published in 2003, evaluated ganciclovir vs no treatment in a sixweek randomized trial. The primary goal of this trial was to determine the effects of treatment on symptomatic infants with CNS involvement. Intravenous ganciclovir, dosed at $6 \mathrm{mg} / \mathrm{kg} /$ dose every 12 hours for six weeks, or no treatment was studied in 100 infants. Hearing preservation in those with normal hearing and hearing improvement in those affected were evaluated at six months. The results of the study demonstrated that six weeks of ganciclovir improved hearing outcomes at six months. Specifically, 84 percent of ganciclovir recipients had improved or at least protected hearing at six months, compared to 59 percent in those who were not treated. Moreover, none of the treated infants had hearing deterioration at six months, compared to 41 percent of the nontreated group. Upon further evaluation, 21 percent of those in the treatment group had worsened hearing in their best ear between baseline and one year or greater of follow-up, compared to 68 percent in the nontreatment group. Of note, clinically significant neutropenia was seen in 63 percent of treated patients, as compared to 21 percent in nontreated patients. ${ }^{28}$ With the release of valganciclovir, the oral prodrug of ganciclovir, Kimberlin and associates then evaluated the pharmacokinetics and pharmacodynamics and found that a dose of $16 \mathrm{mg} / \mathrm{kg} /$ dose twice daily reliably provided comparable systemic concentrations to intravenous ganciclovir. ${ }^{29}$ This benefit avoids the need for long-term intravenous access, along with the complications and expense involved.

As prolonged viral shedding occurs in infected infants and some infants present with delayed sequalae, it was hypothesized that a longer duration of antiviral treatment may result in improved outcomes. ${ }^{30}$ A study conducted by Kimberlin and colleagues was published comparing six weeks to six months of oral valganciclovir in symptomatic infants, all 30 days of age or less at diagnosis, with or without CNS involvement. ${ }^{30}$ The primary endpoint of the study was the change in best-ear hearing from baseline to six months. Secondary endpoints included the change in hearing from baseline to 12 and 24 months, as well as neurodevelopmental outcomes on the same evaluation. The notable results showed that longer duration of antiviral therapy modestly improved hearing function at 12 and 24 months but not at the six-month evaluation. At 24 months, the six-month group also had better neurodevelopmental scores. Additionally, six weeks of oral valganciclovir was associated with a lower risk of neutropenia as compared to six weeks of IV ganciclovir, 19 percent vs 63 percent, respectively. ${ }^{30,31}$ The occurrence of neutropenia with oral valganciclovir vs IV ganciclovir administered from six weeks to six months was 21 percent vs 27 percent, respectively. ${ }^{31}$ Based on the results of this study, oral valganciclovir is, for now, considered an effective and well-tolerated therapeutic option for symptomatic infants to improve hearing and long-term neurodevelopmental outcomes. Table 2 provides treatment recommendations, adverse effects, and monitoring.

Because they have not been included in any studies, there is no evidence for the benefit of antiviral therapy in asymptomatic infants. As described previously, in the 85-90 percent of infected yet asymptomatic infants, 10-15 percent will have long-term complications, primarily SNHL. While much effort has been made to identify a neonatal biomarker of these complications, these energies have proven unsuccessful. At this time, viral load data from peripheral blood is receiving the most focused study, but the data is incomplete. There is a phase II, open-label trial evaluating the use of valganciclovir to prevent development of SNHL in infants with asymptomatic cCMV (ClinicalTrials.gov NCT03301415). The primary objective of the study is to estimate the proportion of subjects with asymptomatic cCMV infection who, 


\begin{tabular}{|c|c|c|}
\hline Disease Manifestation & Treatment Recommendation & Adverse Effects/Monitoring \\
\hline \multicolumn{3}{|l|}{ CNS Disease } \\
\hline Microcephaly, CNS calcification, chorioretinitis & Ganciclovir $6 \mathrm{mg} / \mathrm{kg} /$ dose every 12 hours for & Neutropenia: \\
\hline White matter changes & six weeks & \multirow{2}{*}{$\begin{array}{l}63 \% \text { incidence with intravenous } \\
\text { ganciclovir (six weeks) }{ }^{28,30}\end{array}$} \\
\hline Other severe disease & or & \\
\hline $\begin{array}{l}\text { Life-threatening or severe single-organ or } \\
\text { multiorgan disease }\end{array}$ & $\begin{array}{l}\text { Valganciclovir } 16 \mathrm{mg} / \mathrm{kg} / \text { dose every } 12 \text { hours } \\
\text { for six months }\end{array}$ & $\begin{array}{l}38 \% \text { incidence with intravenous } \\
\text { ganciclovir (two weeks) + oral } \\
\text { ganciclovir (six weeks) })^{29}\end{array}$ \\
\hline \multicolumn{2}{|l|}{ Mild disease } & \multirow{3}{*}{$\begin{array}{l}\text { 19\% incidence with oral valganciclovir } \\
\text { (six weeks); after six weeks, incidence } \\
\text { similar to placebo, up to six } \\
\text { months } \text { s }^{28,30}\end{array}$} \\
\hline $\begin{array}{l}\text { Isolated or transient disease (jaundice, petechiae, } \\
\text { SGA in isolation, max of two abnormalities) }\end{array}$ & No treatment & \\
\hline \multirow{2}{*}{$\begin{array}{l}\text { No clinical or biochemical findings of disease (+/-) } \\
\text { detectable CMV viremia }\end{array}$} & No treatment & \\
\hline & & \multirow{3}{*}{$\begin{array}{l}\text { Monitoring: } \\
\text { CBC, electrolytes, BUN, SCr, LFTs weekly } \\
\text { for four weeks, then every month }\end{array}$} \\
\hline Isolated hearing deficit & Ganciclovir/valganciclovir for six months & \\
\hline $\begin{array}{l}\text { "Moderate" disease (multiple findings consistent } \\
\text { with CMV disease) }\end{array}$ & Consider treatment for six weeks to six months & \\
\hline
\end{tabular}

Abbreviations: $\mathrm{BUN}=$ blood urea nitrogen; $\mathrm{CBC}=$ complete blood count; $\mathrm{CMV}=$ cytomegalovirus; $\mathrm{CNS}=$ central nervous system; $\mathrm{LFTs}=$ liver function tests; $\mathrm{SCr}=$ serum creatinine; $\mathrm{SGA}=$ small for gestational age.

Source: Adapted from Luck SE, Wieringa JW, Blazquez-Gamero D, et al. Congenital cytomegalovirus-A European expert consensus statement on diagnosis and management. Pediatr Infect Dis J. 2017;36(12):12. Used with permission.

following treatment with four months of oral valganciclovir, develop SNHL by six months of life. A secondary endpoint is the development of SNHL over 18 months. The results of this trial may help to determine which asymptomatic infants could benefit from oral antiviral treatment.

\section{PROGNOSIS}

Determining the clinical impact of cCMV infection is challenging because of the difficulty in identifying which children will go on to have permanent sequelae. While infants with severe symptomatic infections are likely to develop permanent disability, there is currently no reliable method to predict outcomes in infants with mild to moderate symptoms or those who are asymptomatic. A small study reviewed the viral loads of asymptomatic infants and determined that viral loads at birth that are $\geq 17,000$ copies $/ \mathrm{mL}$ were more likely to develop SNHL. ${ }^{32}$ However, this study was limited in size, and a larger study needs to be performed to further delineate this marker as a predictor of permanent morbidity.

\section{SUMMARY}

Cytomegalovirus was first identified over 50 years ago as the cause of a congenitally acquired infection, affecting $0.5-2$ percent of all live births and is the main nongenetic cause of SNHL and neurologic damage. As the risk of cCMV is highest during the first 20 weeks of gestation, prevention would be ideal. Currently, the most effective way to achieve this is with routine prenatal education specific to proper hygiene and associated risks. A national initiative that educates and encourages proper hygiene, starting with pregnancy planning and continuing through infancy could have a significant impact on maternal and subsequent congenital infection and is worth the concerted efforts of all health care providers. Both immune globulin and vaccination against CMV continue to be researched; however, no reliable method of medical prevention has been proven. Although there are reliable screening tools for viral shedding in newborns, we lack universal screening recommendations. While there have been a few cases where antivirals have been administered to pregnant women with good outcomes, there are currently no recommendations. Treatment of symptomatic newborns consists of oral valganciclovir for six months; this has been proven effective in reducing hearing loss as well as other sequelae, but it is not without risk. Although much effort has and is being expended to identify at-risk but asymptomatic infants who may benefit from antiviral therapy, we lack conclusive information with which to direct care. While we have gained much knowledge about cCMV and its consequences over that last half-century, many solutions to the problems caused by this virus remain elusive. We can only hope that a combination of improved education and prevention, reliable and early recognition of at-risk patients, and effective antiviral therapy will minimize the number of children adversely affected by this organism.

\section{REFERENCES}

1. Liu G, Hai R, Liu F. Detection of congenital cytomegalovirus in newborns using nucleic acid amplification techniques and its public health implications. Virol Sinica. 2017;32(5):376-386. https://doi.org/ $10.1007 / \mathrm{s} 12250-017-4055-\mathrm{y}$

2. James SH, Kimberlin DW. Advances in the prevention and treatment of congenital cytomegalovirus infection. Curr Opin Pediatr. 2016;28(1):8185. https://doi.org/10.1097/MOP.0000000000000305

3. Marisco C, Kimberlin DW. Congenital cytomegalovirus infection: Advances and challenges in diagnosis, prevention and treatment. Ital J Pediatr. 2017;43:38. https://doi.org/10.1186/s13052-0170358-8 
4. Smith MG. Propagation in tissue cultures of cytopathogenic virus from human salivary gland virus disease. Proc Soc Exp Biol Med. 1956;92:424. https://doi.org/10.3181/00379727-92-22498

5. Hanshaw JB. Congenital and acquired cytomegalovirus infection. Pediatr Clin North Am. 1966;13(2):279-293. https://doi.org/10.1016/ S0031-3955(16)31838-7

6. Kluge RC, Wicksman RS, Weller TH. Cytomegalic inclusion disease of the newborn: Report of case with persistent viruria. Pediatrics. 1960;25:35-39.

7. Kachikis A, Ecket LO, Englund J. Who's the target: Mother or baby? Viral Immunol. 2017;31(2):184-194. https://doi.org/10.1089/ vim.2017.0135

8. Saldan A, Forner G, Mengoli C, Gussetti N, Palù G, Abate D. Testing for cytomegalovirus in pregnancy. J Clin Microbiol. 2017;55:693-702. https://doi.org/10.1128/JCM.01868-16

9. Luck SE, Wieringa JW, Blazquez-Gamero D, et al. Congenital cytomegalovirus-A European expert consensus statement on diagnosis and management. Pediatr Infect Dis J. 2017;36(12):1205-1213. https://doi.org/10.1097/INF.0000000000001763

10. Faure-Bardon V, Magny JF, Parodi M, et al. Sequelae of congenital cytomegalovirus following maternal primary infections are limited to those acquired in the first trimester. Clin Infect Dis. 2019;69(9):15261532. https://doi.org/10.1093/cid/ciyl128

11. Walter-Nicolet E, Leblanc, M, Leruez-Ville M, Hubert P, Mitanchez D. Congenital cytomegalovirus infection manifesting as neonatal persistent pulmonary hypertension: Report of two cases. Pulm Med. 2011; Article ID 293285. https://doi.org/10.1155/2011/293285

12. Columba C, Giuffre M, La Place S, et al. Congenital cytomegalovirus related intestinal malrotation: A case report. Italian $J$ Pediatr. 2016;42:105. https://doi.org/10.1186/s13052-016-0318-8

13. Sobolewska-Pilarczyk, M, Pawlak-Osiunska K, Drewa S, Smok B, Pawlowska M. Intraventricular haemorrhage as the first manifestation of congenital cytomegalovirus infection. Indian J Med Microbiol. 2018;36(2):279-281. https://doi.org/10.4103/ijmm.IJMM_18_11

14. Osatalkul S, Changong A, Pruekprasert P. Congenital cytomegalovirus infection presenting with isolated secretory diarrhea mimicking a congenital diarrhoeal disorder. J Paediatr Child Health. 2018;54(4):460. https://doi.org/10.1111/jpc.13896

15. Muruganath S, Padmaraj R, Gopalakrishnan N, et al. Isolated renal involvement of cytomegalovirus inclusion disease in an infant. Saudi J Kidney Dis Transpl. 2018;29(1):198-201. https://doi. org/10.4103/1319-2442.225176

16. Inagaki $\mathrm{K}$, Blackshear $\mathrm{C}$, Hobbs $\mathrm{CV}$. Bronchopulmonary dysplasia in very preterm infants with symptomatic congenital cytomegalovirus infection: A propensity score-matched analysis. J Pediatr. 2019;204:142-147. https://doi.org/10.1016/j.jpeds.2018.08.038

17. Revello, MG, Tibaldi C, Masuelli G, et al. Prevention of primary cytomegalovirus infection in pregnancy. EBioMedicine. 2015;2:12051210. https://doi.org/10.1016/j.ebiom.2015.08.003

18. Kagan KO, SonekJ, Hamprecht K. Antenatal treatmentoptions for primary cytomegalovirus infections. Curr Opin Obstet Gynecol. 2018;30:355360. https://doi.org/10.1097/GCO.0000000000000486

19. Revello MG, Lazzarotto T, Guerra B, et al. A randomized trial of hyperimmune globulin to prevent congenital cytomegalovirus. $N$ Engl J Med. 2014;370(14):1316-1326. https://doi.org/10.1056/ NEJMoal310214

20. Bialas KM, Permar SR. The march towards a vaccine for congenital CMV: Rational and models. PLoS Pathog. 2016;12(2):e1005355. https:// doi.org/10.1371/journal.ppat.1005355
21. Guerra B, Simonazzi G, Puccetti C, et al. Ultrasound prediction of symptomatic congenital cytomegalovirus infection. Am J Obstet Gynecol. 2008;198(4):380.el-e7. https://doi.org/10.1016/j.ajog.2007.09.052

22. Enders M, Daiminger A, Exler S, Enders G. Amniocentesis for prenatal diagnosis of cytomegalovirus infection: Challenging the 21 weeks' threshold. Prenat Diagn. 2017;37(4):389-398. https://doi.org/ $10.1002 / \mathrm{pd} .5025$

23. Ross SA, Ahmed A, Palmer AL, et al. Detection of congenital cytomegalovirus infection by real-time polymerase-chain-reaction analysis of saliva or urine specimens. J Infect Dis. 2014;210(9):14151418. https://doi.org/10.1093/infdis/jiu263

24. Boppana SB, Ross SA, Shimamura M, et al. Saliva polymerase-chainreaction assay for cytomegalovirus screening in newborns. $N$ Engl J Med. 2011;364(22):2111-2118. https://doi.org/10.1056/NEJMo al006561

25. Boppana SB, Ross SA, Novak Z, et al. Dried blood spot real-time polymerase-chain-reaction assays to screen newborns for congenital cytomegalovirus infection. JAMA. 2010;202(3):297.el-e8. https:// doi.org/10.1097/OGX.0b013e3181f0795b

26. Seidel E, Feiterna-Sperling C, Siedentopf JP, et al. Intrauterine therapy of cytomegalovirus infection with valganciclovir: Review of the literature. Med Microbiol Immunol. 2017;206(5):347-354. https:// doi.org/10.1007/s00430-017-0512-3

27. Leruez-Ville M, Ghout I, Bussieres L, et al. In utero treatment of cytomegalovirus infection with valacyclovir in a multicenter, open-label, phase II study. Am J Obstet Gynecol. 2016;215(4):462.e10. https:// doi.org/10.1016/j.ajog.2016.04.003

28. Kimberlin DW, Lin CY, Sanchez PJ, et al. Effect of ganciclovir therapy on hearing in symptomatic congenital cytomegalovirus disease involving the central nervous system: A randomized, controlled trial. J Pediatr. 2003;143(1):16-25. https://doi.org/10.1016/ S0022-3476(03)00192-6

29. Kimberlin DW, Acosta EP, Sanchez PJ, et al. Pharmacokinetic and pharmacodynamic assessment of oral valganciclovir in the treatment of symptomatic congenital cytomegalovirus disease. J Infect Dis. 2008;197(6):836-845. https://doi.org/10.1086/528376

30. Kimberlin DW, Jester PM, Sanchez PJ, et al. Valganciclovir for symptomatic congenital cytomegalovirus disease. N Engl J Med. 2015;372(10):933-943. https://doi.org/10.1056/NEJMoal404599

31. Hui L, Wood G. Perinatal outcome after maternal primary cytomegalovirus infection in the first trimester: A practical update and counseling aid. Prenat Diagn. 2015;35(1):1-7. https://doi.org/10.1002/pd.4497

32. Fortner G, Abate D, Mengoli C, Palù G, Gussetti N. High cytomegalovirus DNAemia predicts CMV sequelae in asymptomatic congenitally infected newborns born to women with primary infection during pregnancy. J Infect Dis. 2015;212(1):67-71. https://doi.org/ 10.1093/infdis/jiu627

\section{About the Author}

Jim Thigpen, PharmD, BCPS, is an associate professor at the East Tennessee State University Bill Gatton College of Pharmacy in Johnson City, Tennessee, and has been a pediatric clinical pharmacist for 30 years.

For further information, please contact:

Jim Thigpen, PharmD, BCPS

ETSU Bill Gatton College of Pharmacy

Johnson City, TN, USA

E-mail: thigpen@etsu.edu 